\title{
Nerve Surgeons' Assessment of the Role of Eduard Pernkopf's Atlas of Topographic and Applied Human Anatomy in Surgical Practice
}

\author{
Andrew Yee, Ph.D.; Demetrius M. Coombs, M.D.; Sabine Hildebrandt, M.D.; \\ William E. Seidelman, M.D.; J. Henk Coer, M.D., Ph.D.; and Susan E. Mackinnon, M.D.
}

Pernkopf's Atlas of Anatomy contains anatomical plates with detailed images of the peripheral nerves. Its use is controversial due to the author's association with the "Third Reich" and the potential depiction of victims of the Holocaust. The ethical implications of using this atlas for informing surgical planning have not been assessed. Our objectives were: (1) assess the role of Pernkopf's atlas in nerve surgeons' current practice, and (2) determine whether a proposal for its ethical handling may provide possible guidance for use in surgery and surgical education.

Published in NEUROSURGERY, Volume 84, Number 2, February 2019.

Presented at the American Society of Peripheral Nerve, 27th Annual Meeting, Phoenix, Arizona, January 12-14, 2018.

Copyright (C2018 by the Congress of Neurological Surgeons, Republished in the JBC with permission.

Approval for reuse required from original publisher

BACKGROUND: Pernkopf's atlas of anatomy contains anatomical plates with detailed images of the peripheral nerves. Its use is controversial due to the author's association with the "Third Reich" and the potential depiction of victims of the Holocaust.
The ethical implications of using this atlas for informing surgical planning have not been assessed.

OBJECTIVE: To (1) assess the role of Pernkopf's atlas in nerve surgeons' current practice and (2) determine whether a proposal for its ethical handling may provide possible guidance for use in surgery and surgical education.

METHODS: Members of American Society for Peripheral Nerve and PASSIO Education (videobased learning platform) were surveyed and 182 responses collected. The survey introduced the historical origin of Pernkopf's atlas, and respondents were asked whether they would use the atlas under specific conditions to serve as a recommendation for its ethical handling. An anatomical plate comparison between Netter's and Pernkopf's atlases was performed to compare anatomical accuracy and surgical utility.

RESULTS: Fifty-nine percent of respondents were aware of Pernkopf's atlas, with 13\% currently using it. Aware of the historical facts, $69 \%$ were comfortable using the atlas, $15 \%$ uncomfortable, and $17 \%$ undecided. Additional information on conditions for an ethical approach to the use of the atlas led $76 \%$ of those "uncomfortable" and "undecided" to becoming "comfortable" with use.

CONCLUSION: While the use of Pernkopf's atlas remains controversial, a proposal detailing conditions for an ethical approach in its use provides new guidance in surgical planning and education. 
KEYWORDS: Pernkopf, Surgery, Ethics, Anatomy Atlas, Anatomical Illustration, Nerve

\section{INTRODUCTION}

Eduard Pernkopf 's Atlas of Topographical and Applied Human Anatomy ${ }^{1}$ was first published in its German version between 1937 and 1960, and the first American version in 1963. Publication ceased in 1994 due to the revelation in the mid-1980s and 1990s of the author's participation in the National Socialist (Nazi) regime and the possible use of executed victims from the Third Reich. ${ }^{1-8}$ The atlas was widely known by anatomists and surgeons for its intricacy and "regional stratigraphic" approach, which involves multiple layers of dissection from superficial to deep, with an emphasis on fascial relationships that are often missing from comparable anatomical atlases. ${ }^{9}$ Because of its historical connection with the criminal Nazi regime, Pernkopf's atlas has been the basis of ethics discussions surrounding its use as teaching material in the anatomical sciences, ${ }^{10-13}$ but continues to circulate as a used book, and is anecdotally known for providing anatomical utility in some surgical communities. This presents ethical challenges for its use in patients who need complex surgery. ${ }^{14}$ The purpose of this study is to (1) assess the role of Pernkopf 's atlas in nerve surgeons' current practice and (2) determine whether an ethical proposal to highlight the history of the atlas could provide possible guidance for its use in surgery and surgical education.

Eduard Pernkopf (1888-1955) and the atlas's illustrators were devoted members of the Nazi party (Nationalsozialistische Deutsche Arbeiterpartei) and/or soldiers in World War II. ${ }^{8}$ Pernkopf, the Director of the Viennese Anatomical Institute, was appointed as Dean of the Medical Faculty in 1938, directly after the annexation of Austria by Nazi Germany, and served as President of the University of Vienna from 1943 to 1945 . $^{6}$ In his role as Dean, he oversaw the dismissal of 157 of the 197 members of the medical faculty. Most emigrated, some died at their own hand or were murdered in concentration camps. ${ }^{15}$ The medical illustrators demonstrated their Nazi allegiance by including Swastikas and lightning-bolt SS (Schutzstaffel) symbols in their signatures on the paintings. ${ }^{8}$ Pernkopf 's and the illustrators' significant Nazi involvement was confirmed in an investigation of the origin of the bodies depicted in the paintings, which was authorized by the Senate of the University of Vienna in $1998 .^{3}$

This Senatorial Project was designed to resemble an earlier historical self-assessment by an anatomical institute (University of Tübingen) with the objectives to (1) investigate the origin and destiny of the bodies used by Pernkopf and (2) to determine the extent of his Nazi party membership and political activities. ${ }^{5}$ The findings of the Senatorial Project revealed that 3964 bodies of adults were unclaimed, 7 donated, and at least 1377 bodies were executed prisoners, who were victims of the Nazis' unjust legislation. There was no evidence that bodies were sourced from concentration camps close to Vienna, despite such bodies being transported to a different Austrian anatomical institute. ${ }^{4,5}$ Of the 791 illustrations produced for the atlas, 41 plates were definitively based on the bodies of executed victims, with the origin of approximately 350 plates remaining unclear. ${ }^{4}$ While traditional, legal anatomical body procurement included unclaimed bodies from public institutions, among them executed prisoners and persons who committed suicide, the number of executions rose exponentially under the Nazi regime due to new legislation. $^{16}$

Because of this history, the use of Pernkopf 's atlas for complex surgical planning presents significant ethical challenges. ${ }^{13,14}$ Furthermore, an assessment of the current role of the atlas in a surgeon's practice does not exist. This study represents a focused assessment in nerve surgery due to the intricate portrayal of complex nerve anatomy in Pernkopf 's atlas. While anatomical atlases vary widely with respect to detail, dissection, topography, artistic rendition, and overall design, ${ }^{2,17-24}$ Pernkopf 's atlas has been considered as a "masterpiece" in the 
anatomical sciences, even if indeed a "troubled masterpiece." 8

A goal of this investigation is to assess whether Pernkopf 's atlas provides anatomical accuracy and surgical utility, as judged by nerve surgeons, in comparison with another prominent atlas (Netter's Atlas of Human Anatomy ${ }^{19}$ ) through a visual plate comparison. $^{25}$ In a next step, surgeons where informed about a proposal for a potential ethically justified use of Pernkopf 's atlas and asked, if this information would change their decision to "use" or "not to use" the atlas. This proposal is based on recent discussions on the handling of human remains and data from the Holocaust era, discussions that included the Pernkopf paintings. ${ }^{26-28}$ The findings from this study serve as a recommendation from nerve surgeons for the ethical handling of Pernkopf 's atlas in surgery.

\section{METHODS}

\section{Selection and Description of Participants}

An electronic questionnaire was designed using an online survey tool (SurveyGizmo, (https://www.surveygizmo.com) and distributed via email to members of the American Society for Peripheral Nerve (ASPN) and PASSIO Education (https://www.passioeducation.com/). PASSIO Education is an online video-based learning program/platform for international nerve surgeons. Data were collected from April 10, 2017 through July 7, 2017. Recruitment of participants was performed by an initial email invitation to each group (ASPN, PASSIO), followed by 2 reminder emails before the survey was closed. No incentives for survey participation were offered. This study (\#201702009) was approved by the Institutional Review Board of Washington University School of Medicine in St. Louis, Missouri.

\section{Survey Design}

The survey was composed of 2 parts: (1) surgical assessment and ethical handling of Pernkopf 's atlas and (2) demographics, anatomical resources, and anatomical plate comparisons. The first part included a maximum of 11 questions with embedded survey logic to prevent exposure of repeated questions to reduce survey fatigue. Respondents were exposed to the historical findings of the Senatorial Project for assessment. ${ }^{3-5}$ Special consideration was given to avoid exposure to Pernkopf illustrations for individuals who responded as being "uncomfortable" with the use of the atlas. Following the assessment, participants were given a scenario for a decision to "use" or "not to use" if certain ethical conditions were met. A "4-point proposal" was developed, which includes (1) formal disclosure discussing the historical origin and ethical challenges, (2) consensus from bioethicists validating its specific use for benefiting the lives of patients, (3) consensus from BetDin (Jewish religious rabbinical court) that is consistent with the Jewish principle, Piku'ach nefesh, which describes, under certain conditions, the preservation of human life overrides any other religious consideration, ${ }^{27}$ and (4) an official memorial commemorating the victims portrayed in the atlas. Responses from the previous assessment were compared to responses following the 4-point proposal to determine its effectiveness.

The second survey part included a maximum of 10 demographic and 2 anatomical resource questions and 6 plate comparisons. Six plates were selected, ${ }^{25}$ each from Netter's and Pernkopf 's atlases ${ }^{1,19}$ that demonstrated comparable structures, anatomical orientation, and relevance to nerve surgery to ensure a standardized comparison. Images were scanned at high-resolution, identifiable labels removed, and "white-balanced" to ensure proper image quality. Before the plate comparison, participants underwent a descriptive tutorial with an optional video and logic question to ensure the appropriate computer skill to view both Netter's and Pernkopf 's plate. Netter's and Pernkopf 's plates were randomized with either left or right positioning in each comparison. An estimated length of 12 minutes was calculated for completion of the entire survey. 


\section{Statistical Analysis}

All statistical analyses ( $P$-values) on the plate comparison data were performed using SPSS Statistical Software (version 23, IBM, Armonk, New York). Proportions of surgeons, who perceived images as having greater anatomical accuracy and greater surgical utility, were given the null hypothesis of 50/50.

\section{RESULTS}

\section{Demographics}

One hundred eighty-two responses were collected (25\% response rate, $77 \%$ completion rate, $35 \%$ ASPN, 65\% PASSIO). Of the respondents, 83\% were male and $17 \%$ female; ages ranged from 26 to 73 yr old; $16 \%$ were resident physicians, 12\% surgical fellows, and $72 \%$ practicing surgeons. Additional demographic data pertaining to continent-of-origin, race, religious beliefs, surgical specialty, and years-of-practice were obtained (Table 1).

\section{Awareness and Usage of Pernkopf's Atlas in Nerve Surgery}

Of the respondents, 59\% were aware of Pernkopf 's atlas. Of those aware, $41 \%$ had used it previously; $22 \%$ were currently using it; $77 \%$ were aware of the atlas's historical origin (Table 2). Of those historically aware of the origin of the atlas, $66 \%$ reported "some general knowledge" concerning the abusive actions of German physicians during the Third Reich with $10 \%$ and $24 \%$, respectively, reporting having "very little" or a "great deal" of knowledge. These numbers are similar for practicing surgeons and trainees, except for $31 \%$ of practicing surgeons reporting knowing a "great deal" compared to only $6 \%$ of trainees.

\begin{tabular}{|c|c|}
\hline Societies & Proportion (\%) \\
\hline American Society for Peripheral Nerve (ASPN) & 35 \\
\hline $\begin{array}{l}\text { PASSIO Education (PASSIO, } \\
\text { passioeducation.com) }\end{array}$ & 65 \\
\hline Gender & Proportion (\%) \\
\hline Male & 83 \\
\hline Female & 17 \\
\hline Age & Years \\
\hline Age & 26-73 (avg. 43) \\
\hline Continent of Origin & Proportion (\%) \\
\hline North America & 45 \\
\hline South America & 5 \\
\hline Europe & 27 \\
\hline Asia & 16 \\
\hline Africa & 5 \\
\hline Australia & 2 \\
\hline Race & Proportion (\%) \\
\hline Asian & 13 \\
\hline Black & 1 \\
\hline East Indian & 2 \\
\hline Latino/Hispanic & 8 \\
\hline Middle Eastern & 9 \\
\hline White & 63 \\
\hline Biracial & 1 \\
\hline Multiracial & 4 \\
\hline Other & 1 \\
\hline Religious Beliefs & Proportion (\%) \\
\hline Agnostic & 14 \\
\hline Atheist & 11 \\
\hline Buddhist/Taoist & 2 \\
\hline $\begin{array}{l}\text { Christian (Catholic, Orthodox, Protestant, } \\
\text { Latter Day Saints, Other) }\end{array}$ & 39 \\
\hline Hindu & 4 \\
\hline Jewish & 13 \\
\hline Muslim/Islam & 10 \\
\hline Spiritual & 4 \\
\hline Prefer Not to Answer & 1 \\
\hline Other & 2 \\
\hline Position & Proportion (\%) \\
\hline Resident or Fellow Surgeon & 28 \\
\hline Practicing Surgeon & 72 \\
\hline Surgical Specialty/Practice Type & Proportion (\%) \\
\hline Hand Surgery & 55 \\
\hline Neurological Surgery & 19 \\
\hline Orthopedic Surgery & 28 \\
\hline Plastic and Reconstructive Surgery & 45 \\
\hline Other & 7 \\
\hline Practice Duration & Years \\
\hline Years-in-Practice & 1-39 (avg. 14) \\
\hline
\end{tabular}


TABLE 2. Survey Responses on the use or Not to Use Pernkopf's Atlas in Nerve Surgery

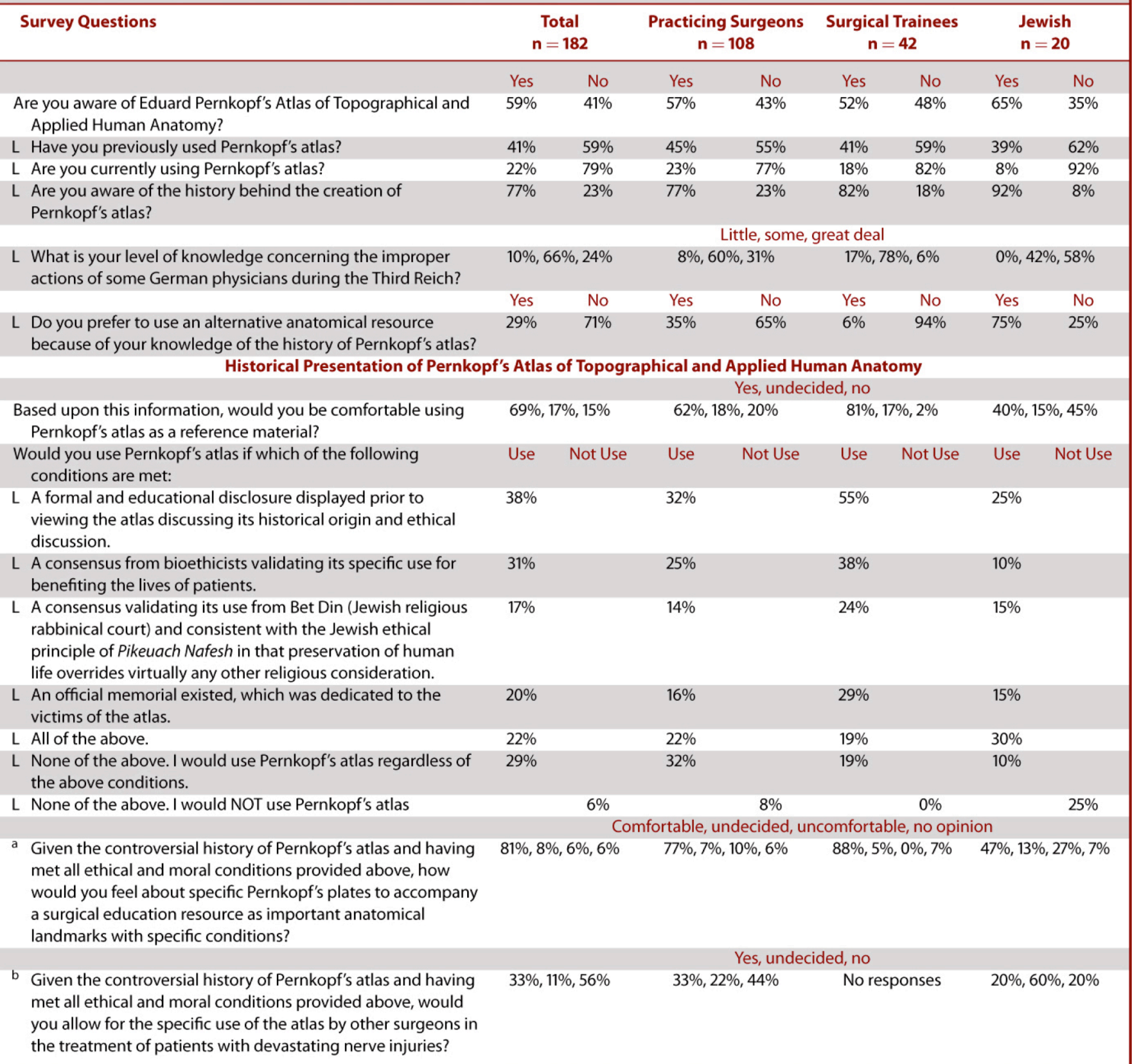

Table 2 Key: L - Survey logic, which displays the question to the participant based on the previous proper question (e.g., "yes" to the "awareness" question displays the question of "previous use"). Therefore, denoted survey answers are a subpopulation of the previous proper question (e.g., "41\% yes" to "previous use" question is a subpopulation of the "59\% yes" of the "awareness" question).

a Survey logic specific to the "use" group.

b Survey logic specific to the "not use" group. 


\section{Influence of a 4-Point Ethical Proposal}

Following an explanation of the history surrounding Pernkopf 's atlas, 69\% of respondents felt comfortable using it as reference material, with $17 \%$ undecided and 15\% uncomfortable (Figure).

Respondents were then asked if they would use Pernkopf 's atlas under any of 4 ethical conditions:

(1) $38 \%$ would "use" the atlas in conjunction with a formal and educational disclosure prior to viewing the atlas, (2) $31 \%$ with having a consensus from bioethicists validating its use to benefit patient care, (3) $17 \%$ after a Bet Din consensus validating Piku'ach nefesh, ${ }^{27}$ (4) $20 \%$ with having an official memorial commemorating the victims of the atlas, and $22 \%$ with having met all of the above conditions; $29 \%$ of respondents would use Pernkopf 's atlas regardless of those conditions; and finally $6 \%$ of respondents would not use Pernkopf 's atlas irrespective of those conditions. Of the respondents who were initially "undecided" or "uncomfortable" in using the atlas, 93\% and 59\%, respectively, changed their decision to "use" of the atlas following the 4-point proposal, with an average of $76 \%$.

\section{Surgical Education and Use by Others to Benefit Patients with Nerve Injuries}

Respondents who were comfortable with the use of the atlas following the 4-point proposal were then asked whether the images could be used to teach important anatomical landmarks alongside the surgical videos on PASSIO Education (https://surgicaleducation.wustl.edu/category/surgic al-procedures/ if the following conditions were met: (1) no financial profit would be made from the images, (2) the images could not be downloaded, (3) full disclosure in a preface documenting the historical origin and ethical challenges of Pernkopf's atlas, and (4) a hyperlink to the official information and memorial relating to the atlas; $81 \%$ reported being comfortable, $8 \%$ undecided, $6 \%$ uncomfortable, and $6 \%$ no opinion. Respondents who would not use the atlas despite the 4-point proposal were asked whether they would allow other surgeons to use the atlas to benefit patients with devastating nerve injuries; 33\% reported yes, 56\% no, and $11 \%$ were undecided.

\begin{tabular}{|lc|}
\hline TABLE 3. Type of Anatomical Resources Used in Nerve Surgery \\
\hline Type of Anatomical Resources Used & Proportion \\
\hline Anatomical Atlases & $81 \%$ \\
Specialized Surgical Textbooks & $86 \%$ \\
Original Research \& Clinical Journal Articles & $65 \%$ \\
Societal Educational Resources & $29 \%$ \\
Internet Resources & $76 \%$ \\
Other & $4 \%$ \\
\hline
\end{tabular}

\section{Responses from Surgeons of Jewish Descent}

Respondents who identified as being of Jewish descent $(n=20,13 \%)$ were analysed independently on their awareness, usage, and influence of the 4point proposal. This step was taken because Jews were the main target of Nazi extermination policies in the Holocaust and thus potentially most affected by the use of the atlas. ${ }^{29,30}$ Of the respondents with

\begin{tabular}{lc|}
\hline TABLE 4. Type of Anatomical Atlases Used in Nerve Surgery \\
\hline Type of Anatomical Atlases Used & Proportion \\
\hline Netter's Atlas of Human Anatomy & $81 \%$ \\
Gray's Atlas of Anatomy & $50 \%$ \\
Grant's Atlas of Human Anatomy & $33 \%$ \\
Sobotta's Atlas of Human Anatomy & $24 \%$ \\
Thieme's Atlas of Anatomy & $14 \%$ \\
Pernkopf's Atlas of Topographical and Applied Human & $13 \%$ \\
Anatomy & $12 \%$ \\
Rohen's Photographic Color Atlas of Anatomy & $11 \%$ \\
\hline Other & $7 \%$ \\
Lippincott Williams \& Wilkins' Atlas of Anatomy & $1 \%$ \\
\hline Morris' Human Anatomy: A Complete Systematic Treatise & \\
\hline
\end{tabular}

Jewish descent, 13 (65\%) were aware of Pernkopf 's atlas. Of those aware, 5 (39\%) had used it previously; 1 (8\%) was currently using it, and 12 $(92 \%)$ were aware of the atlas's historical origin. Of those historically aware of the origin of the atlas, $58 \%$ reported knowing a "great deal" concerning the abusive actions of German physicians during the Third Reich, with the remaining $42 \%$ having "some general knowledge." Following a historical explanation of Pernkopf 's atlas, $40 \%$ felt comfortable using it as reference material, with $15 \%$ undecided and $45 \%$ uncomfortable. Respondents 
TABLE 5. Netter's vs Pernkopf's Anatomical Plate Comparison

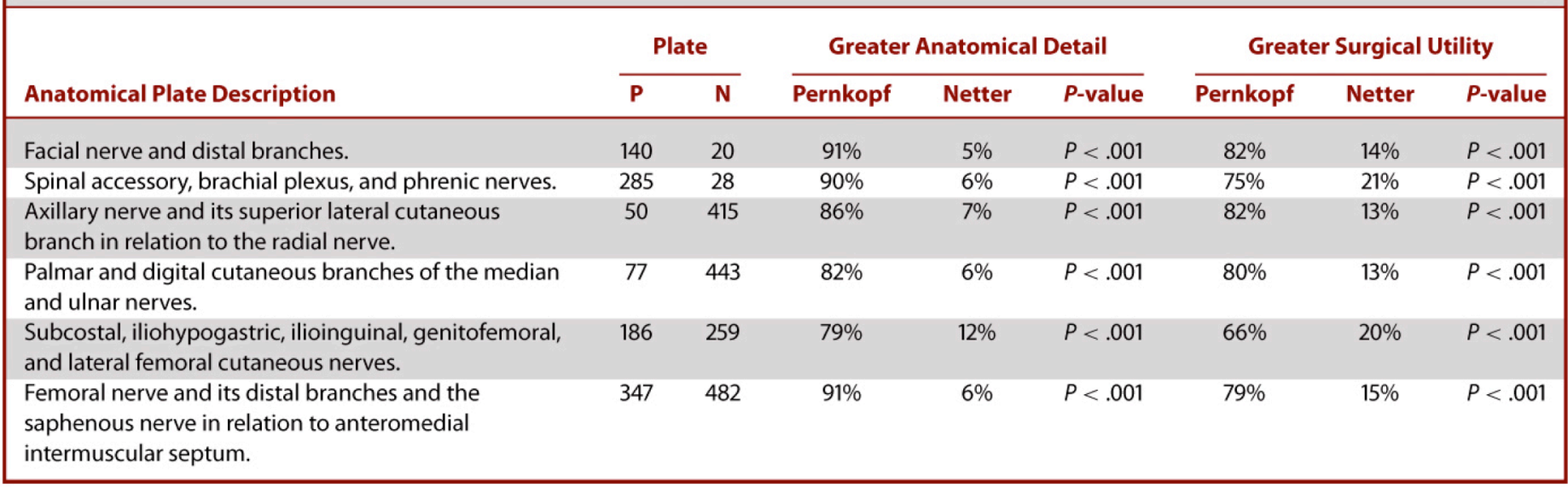

were then provided with the 4-point proposal. Most agreed to the conditional "use" of the images, with $25 \%$ after a formal and educational disclosure, $10 \%$ following a bioethicists consensus, $15 \%$ after a Bet Din consensus validating Piku'ach nefesh, ${ }^{27} 15 \%$ in conjunction with an official memorial, and $30 \%$ if all conditions were met; $10 \%$ of respondents would use Pernkopf 's atlas regardless of those conditions; $25 \%$ of respondents would not use Pernkopf 's atlas irrespective of those conditions.

\section{Use of Anatomical Resources Atlases in Nerve Surgery}

All respondents were asked about the type of anatomical resources they used (Table 3 ). Eightyone percent $(81 \%)$ reported the use of anatomical atlases, $86 \%$ specialized surgical textbooks, $65 \%$ original research/clinical journal articles, 29\% societal educational resources, and $76 \%$ Internet resources. Of the anatomical atlases, ${ }^{2,17-24} 81 \%$ reported using Netter's atlas, 50\% Gray's atlas, 33\% Grant's atlas, 24\% Sobotta's atlas, 14\% Thieme's atlas, 13\% Pernkopf 's atlas, 12\% Rohen's atlas, 7\% Lippincott Williams and Wilkins' atlas, and 1\% Morris' atlas (Table 4).

\section{Netter's vs Pernkopf's Anatomical Plate Comparisons}

Respondents who were "comfortable" with the use of Pernkopf 's atlas following the 4-point proposal were given 6 sets of comparisons between similar Netter's and Pernkopf 's plates (Table 5). The 6 comparisons were prefaced with an emphasis of anatomical nerve structures listed in Table 5. The respondents found Pernkopf 's atlas having both greater anatomical detail (range 79\%-91\%) and greater utility for surgery (range 66\%- $82 \%$ ) when compared with Netter's $(P<.001)$ in all plate comparisons.

\section{Discussion}

No systematic study exists that documents the use of Pernkopf 's atlas in surgery either in the past or present. Even though the former publisher Urban \& Schwarzenberg stopped publication of the work in 1994, there is anecdotal evidence that the atlas is still being used. The historical connection between the book and the Nazi regime presents ethical challenges in its use for intraoperative surgical planning. ${ }^{13,14}$ This study presents an assessment of the use of the atlas by nerve surgeons as well as an evaluation of the potential ethical implications involved. 
Based upon the historical information, how would you feel about using Pernkopf's atlas?

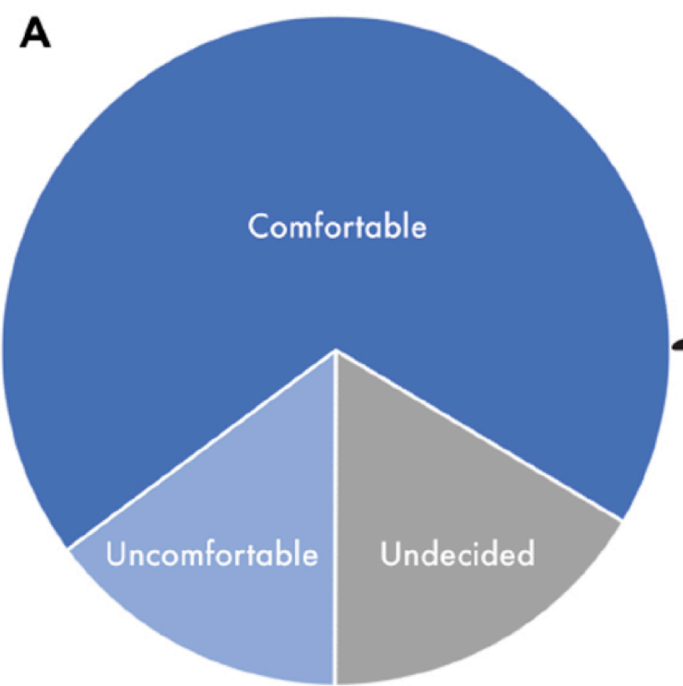

Would you use Pernkopf's atlas if which of the following 4-point ethical considerations are met?

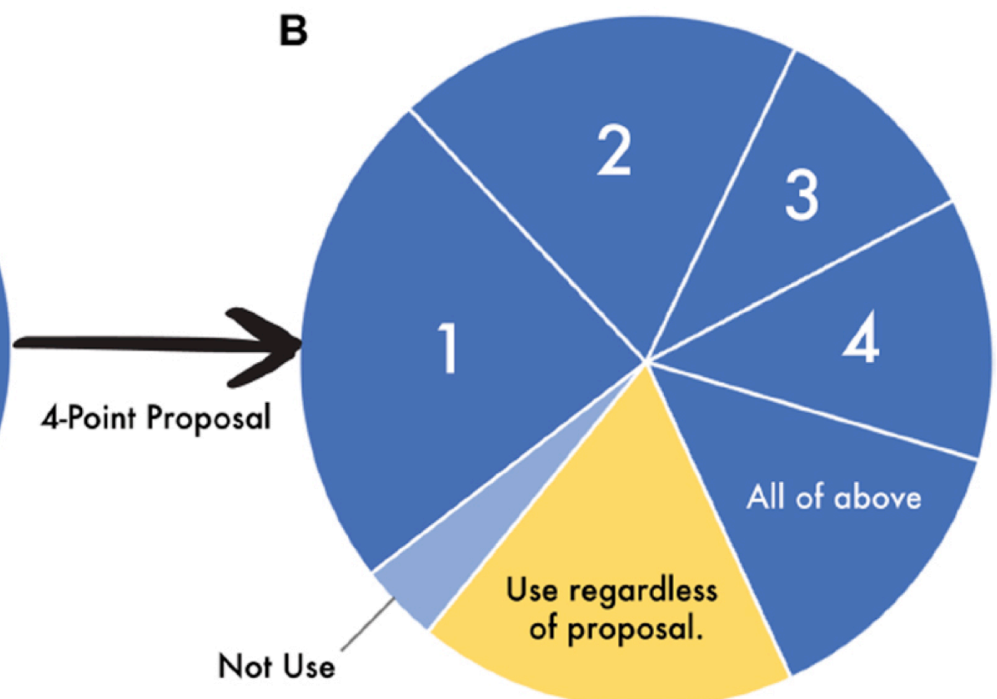

FIGURE. Graphical assessment of Pernkopf's atlas in nerve surgery and the influence of the 4-point ethical proposal on the use of Pernkopf's atlas for surgery and education. A, Respondents were asked whether they were comfortable, undecided, or uncomfortable for using Pernkopf's atlas following a historical presentation. B, Afterwards, respondents were asked under which of the following ethical conditions they would use Pernkopf's atlas: (1) $38 \%$ reported use with a formal and educational disclosing the atlas's historical origin and ethical challenges, (2) $31 \%$ with a consensus from bioethicists validating the specific use for benefiting the lives of patients, (3) $17 \%$ with a consensus from Bet Din (Jewish religious rabbinical court) that is consistent with the Jewish principle, Piku'ach nefesh, which describes, under certain conditions, the preservation of human life overrides any other religious consideration, ${ }^{27}$ (4) $20 \%$ with an official memorial dedicated to the victims of the atlas, and $22 \%$ with all the above conditions. Respondents who were initially "undecided" or "uncomfortable" transitioned to "use" following the 4-point proposal by 93\% and 59\%, respectively.

The response rate $(25 \%)$ was average with respect to surgical societies and includes a risk of nonresponse bias as a limitation of the study. ${ }^{31-33}$ However, the results allow for qualitative conclusions. First and foremost, among them is the fact that a majority of nerve surgeons (59\%) are aware of the atlas and $13 \%$ of the total population currently using it for surgery. Of surgeons that are aware of the atlas, $77 \%$ know about its historical Nazi origin. After presentation of the historical background of the atlas, most surgeons $(69 \%)$ were "comfortable" with the use of Pernkopf 's atlas in surgery, and a minority (15\%) were "uncomfortable."

When surgeons were presented with 4 different ethical conditions that could be met in connection to the use of the atlas, a majority of those previously "undecided" or "uncomfortable" about its use changed their position and were now willing to employ the images in surgery (Figure). While $65 \%$ of surgeons would use Pernkopf 's atlas with the implementation of an ethical proposal, there were $29 \%$ who would use the atlas irrespective of these ethical conditions. The latter finding may derive from the unawareness of the still existing ethical controversy in using Pernkopf 's atlas in surgery, ${ }^{14}$ as a significant percentage of surgeons $(6 \%)$ would not use the Pernkopf atlas under any condition. This percentage is even higher among surgeons of Jewish descent (25\%). Any evaluation of using Nazi medical data, including the paintings of executed prisoners in Pernkopf 's atlas, needs to take account of the perspective of the victims, foremost amongst them Jews as the main target of Nazi persecution. ${ }^{29,30}$ 
Therefore, the survey data from nerve surgeons of Jewish descent were specifically examined. Twenty of the 182 surgeons identified as of Jewish descent, and only 1 of them were currently using the Pernkopf atlas for surgical planning. After the presentation of the historical background of the atlas, there was substantial division of opinion in surgeons of Jewish descent, with 8 (40\%) being comfortable and 9 (45\%) uncomfortable with respect to using Pernkopf 's atlas in surgery. However, after presentation of the 4-point proposal of ethical conditions, surgeons of Jewish descent changed their opinion with 15 (75\%) being comfortable and $5(25 \%)$ remaining uncomfortable in using Pernkopf 's atlas in surgery. Importantly, 73\% of surgeons of Jewish descent would like to see the implementation of the proposal compared to the $65 \%$ of all respondents. As the 4-point proposal can provide a roadmap towards the appropriate handling of Pernkopf 's atlas, the second condition for achieving a consensus from bioethicists can only occur in part by proxy. Discussions within bioethics are continuously evolving and it is the individual's moral responsibility to recognize the outcomes of said discussions before employing the use of the atlas in surgery. ${ }^{14}$

There may exist a shift of opinion for using Pernkopf 's atlas with the introduction of a new generation of surgeons into the workforce. Remarkably, $82 \%$ of surgical trainees would use the atlas in surgery and further adoption (100\%) with the implementation of the 4-point proposal. This result aligns with most trainees finding value for using an advanced anatomical resource for learning surgery ${ }^{34}$ and highlights the importance for discussing ethics in education when the Pernkopf atlas is used. This aligns with another study's finding that medical students would like to discuss Pernkopf's atlas within a bioethics course. ${ }^{25}$

Currently, Pernkopf 's atlas remains one of many choices among atlases and other anatomical resources used by nerve surgeons (Tables 3 and 4). In a comparison of selected images from Netter's atlas, the most often named atlas of use in this study (Table 4), nerve surgeons see greater anatomical detail and surgical utility in Pernkopf 's images
(Table 5). An individual surgeon commented: "Netter's simplicity provides a great basis for surgery, however until seeing the complexity of peripheral nerves in Pernkopf 's, I now understand the reason for its potential use," thus indicating the usefulness of Pernkopf 's atlas in actual surgery, and Netter's atlas as a tool for anatomical orientation. This comment aligns with medical students identifying Netter's as a superior tool for learning compared to Pernkopf 's. ${ }^{25}$ As this study design prioritized the development of a 4-point proposal, the image comparison was performed at the end of the survey. Therefore, motivated cognition may play a role in these results for those that are historically aware of Pernkopf 's atlas. Further comparison studies with other anatomical resources and atlases will explore the value of Pernkopf 's atlas in anatomy and surgery.

The results of these studies come at a time of renewed interest for transparency in tissue ethics. At a 2017 conference on the "Medical ethics in the 70 years since the Nuremberg Code" in Vienna, the question of whether to "use or not to use" data gained from coercive Nazi medical research to benefit the lives of patients was discussed. ${ }^{26}$

Recommendations were made at a symposium by Yad Vashem, the Holocaust Martyrs Authority in Jerusalem, on "How to Deal with Holocaust Era Human Remains" and include the "Vienna Protocol" for when Jewish or possibly Jewish remains are discovered. ${ }^{27}$ In conjunction, we proposed 4 conditional points for the appropriate handling and continued use of Pernkopf 's atlas in surgery and surgical education. This proposal was developed in response to Yad Vashem's request for a commemoration for the potential victims of Nazi terror and an acknowledgement documenting the history of Pernkopf in the atlas. ${ }^{28}$

\section{Conclusion}

Nerve surgeons continue to use Pernkopf 's atlas to inform surgical planning. The 4-point ethical proposal outlined here can be used as guidance for its ethical handling, including a provision to 
memorialize the victims of the horrendous atrocities committed by the Nazi regime. The Pernkopf controversy continues to divide opinions in the world of surgery and elsewhere, which highlights the importance to communicate the atlas's historical origin and the associated ethical challenges for use in surgery.

\section{Disclosures}

Andrew Yee and Susan E. Mackinnon are cofounders of PASSIO Education. The other authors have no personal, financial, or institutional interest in any of the drugs, materials, or devices described in this article.

\section{References}

1. Pernkopf E. Atlas of Topographical and Applied Human Anatomy. Volume 1: Head and Neck. Volume 2: Thorax, Abdomen and Extremities. Philadelphia and London: W.B. Saunders Co.; 1963.

2. Israel HA, Seidelman WE. Nazi origins of an anatomy text: the Pernkopf atlas. JAMA. 1996;276(20):1633.

3. Akademischer Senat der Universität Wien. Senatsprojekt der Universität Wien: Untersuchungen zur Anatomischen Wissenschaft in Wien 1938-1945. Vienna: Akademischer Senat der Universität Wien; 1998 (unpublished manuscript).

4. Angetter DC. Anatomical science at University of Vienna 1938-45. Lancet North Am Ed. 2000;355(9213):1454-1457.

5. Malina P, Spann G. Das Senatsprojekt der Universitaet Wien "Untersuchungen zur Anatomischen Wissenschaft in Wien 1938-1945". Wien Klin Wochenschr. 1999;111:743-753.

6. Weissmann G. Springtime for Pernkopf. Hosp Pract. 1985;20(10):142-168.
7. Williams DJ. The Work of Eduard Pernkopf, et al. Anaheim, CA: 37th Annual Meeting of the Association of Medical Illustrators; 1982.

8. Williams DJ. The history of Eduard Pernkopf 's topographische anatomie des menschen. $J$ Biocommun. 1988;15(2):2-12.

9. Pernkopf E. Topographische Anatomie des Menschen: Lehrbuch und Atlas der regionärstrategischen Präparation. I. Band: Allgemeines, Brust und Brustgliedmasse. Erste Hälfte. Berlin: Urban und Schwarzenberg; 1943.

10. Atlas MC. Ethics and access to teaching materials in the medical library. Med Law. 2000;19(3):463-473.

11. Atlas MC. Ethics and access to teaching materials in the medical library: the case of the Pernkopf atlas. Bull Med Libr Assoc. 2001;89(1):5158.

12. Hubbard C. Eduard Pernkopf 's atlas of topographical and applied human anatomy: the continuing ethical controversy. Anat Rec. 2001;265(5):207-211.

13. Hildebrandt S. How the Pernkopf controversy facilitated a historical and ethical analysis of the anatomical sciences in Austria and Germany: a recommendation for the continued use of the Pernkopf atlas. Clin Anat. 2006;19(2):91-100.

14. Yee A, Zubovic E, Yu J, et al. Ethical considerations in the use of Pernkopf 's Atlas of anatomy: a surgical case study (in preparation). Surgery. 2018, [Manuscript in preparation].

15. Muehlberger K. Enthebungen an der medizinischen. Fakultaet 1938-1945. Wien Klin Wochenschr. 1998;110:115-120.

16. Hildebrandt S. The Anatomy of Murder: Ethical Transgressions and Anatomical Science during the Third Reich. New York: Berghahn Books; 2016. 
17. Morris H. Morris' Human Anatomy: A Complete Systematic Treatise. 11th ed. New York, NY: The lakiston Co.; 1953.

18. Drake R, Vogl AW, Mitchell AW, Tibbitts R, Richardson P. Gray's Atlas of Anatomy. 2nd ed, London: Churchill Livingstone; 2014.

19. Netter FH. Atlas of Human Anatomy. 6th ed. Philadelphia: W. B. Saunders; 2014.

20. Agur AMR,Dalley AF. Grant's Atlas of Anatomy. 13th ed. Philadelphia: Lippincott Williams \& Wilkins; 2012.

21. Gilroy AM, Macpherson BR, Ross LM, Schuenke M, Schulte E, Schumacher U. Atlas of Anatomy. 2nd ed. Stuttgart: Thieme; 2012.

22. Tank PW, Gest TR. Lippincott Williams \& Wilkins Atlas of Anatomy. 1st ed. Philadelphia: Lippincott Williams \& Wilkins; 2008.

23. Rohen JW, Lütjen-Drecoll E, Yokochi C. Color Atlas of Anatomy: A Photographic Study of the Human Body. 7th ed. Philadelphia: Lippincott Williams \& Wilkins; 2010.

24. Paulsen F, Waschke J. Sobotta Atlas of Human Anatomy. 15th ed. München: Urban \& Fischer; 2013.

25. Coombs DM, Peitzman SJ. Medical Students' assessment of Eduard Pernkopf 's Atlas: topographical anatomy of man. Ann Anat. 2017;212:11-16.

26. Hildebrandt S, Seidelman WE. Where do they come from? A call for complete transparency regarding the origin of human tissues in research. ESMO Open. 2017;2(2):e000201.

27. Polak JA. "Vienna Protocol" for when Jewish or Possibly-Jewish human remains are discovered. In: Seidelman WE, Elbaum L, Hildebrandt S, eds. How to Deal with Holocaust Era Human Remains: Recommendations Arising from a Special Symposium. 2017. Available at:
http://www.bu.edu/jewishstudies/files/2018/06/Final -How-to-Deal-with-Holocaust-Era-HumanRemains.pdf April 18, 2018.

28. Cutler DS. Origins of the Pernkopf anatomy atlas. JAMA. 1997;277(14):1122.

29. Ball P. Naming the victims of Nazi medicine. Lancet North Am Ed. 2017;389(10085):2182-2183.

30. Matuchansky C. Naming of the victims of Nazi medicine. Lancet North Am Ed. 2017;390(10098):933.

31. Reinisch JF, Yu DC, Li WY. Getting a valid survey response from 662 plastic surgeons in the 21 st century. Ann Plast Surg. 2016;76(1):3-5.

32. Wasterlain AS, Melamed E, Bello R, Karia R, Capo JT, Science of Variation Group. The effect of price on surgeons' choice of implants: a randomized controlled survey. J Hand Surg [Am].

2017;42(8):593-601. e596.

33. McMahon SR, Iwamoto M, Massoudi MS, et al. Comparison of e-mail, fax, and postal surveys of pediatricians. Pediatrics. 2003;111(4):e299-e303.

34. Mundschenk MB, Odom EB, Ghosh TD, et al. Are residents prepared for surgical cases? Implications in patient safety and education. J Surg Educ. 2018; 75(2): 403- 408.

\section{Acknowledgments}

We honor the memory of the unknown subjects portrayed in the paintings from Pernkopf 's atlas used for the survey and anatomical plate comparisons. We thank Gary Skolnick for his statistical review. 


\section{About the Authors}

\section{Andrew Yee, B.S.}

Division of Plastic and Reconstructive Surgery, Department of Surgery, Washington University School of Medicine

Contact: yeea@wustl.edu

\section{Demetrius M. Coombs, M.D.}

Department of Plastic Surgery, The Cleveland

Clinic, Cleveland, Ohio

\section{Sabine Hildebrandt, M.D.}

Division of General Pediatrics,

Department of Medicine,

Boston Children's Hospital,

Boston, Massachusetts

and

Department of Global Health and Social Medicine, Harvard Medical School,

Boston, Massachusetts

\section{William E. Seidelman, M.D.}

Department of Family and Community Medicine, Temerty Faculty of Medicine, University of Toronto,

Toronto, Ontario, Canada

\section{J. Henk Coert, M.D., Ph.D.}

Department of Plastic, Reconstructive, and Hand

Surgery,

Utrecht University Medical Center,

Utrecht, The Netherlands

\section{Susan E. Mackinnon, M.D.}

Division of Plastic and Reconstructive Surgery, Department of Surgery, Washington University School of Medicine, St. Louis, Missouri

\section{Conflict of Interest Statement}

The Journal of Biocommunication Management Board and Editors believe that transparency in academic research is essential. Our JBC authors are now required to disclose any possible conflict of interest when submitting a manuscript. In accordance with the Journal of Biocommunication's editorial policy, no potential conflict of interest has been reported or declared by the authors.

As noted in the Disclosures section of this article, Andrew Yee and Susan E. Mackinnon are cofounders of PASSIO Education. 